\title{
Ensino de Libras para os Profissionais de Saúde: Uma Necessidade Premente
}

\section{Libras Teaching for Health Professionals: A Pressing Need}

Marcos Torres de Souza ${ }^{1}$

Renato Porrozzi ${ }^{2}$

\section{Resumo}

Os grupos vulneráveis, no Brasil, ainda sofrem impedimentos para terem acesso a serviços básicos fornecidos pela sociedade. Entre estes se destaca o atendimento em saúde, que se torna mais precário para indivíduos pertencentes a tais grupos. Entre estes grupos, os surdos,por muitas vezes, não são atendidos da maneira correta e até mesmo são, em alguns casos, desrespeitados em sua condição, pois os serviços de saúde não possuem profissionais capacitados para um atendimento de excelência a eles. A solução que é discutida neste trabalho, por mostrar ser a mais eficiente e mais sensata, é a inclusão da disciplina de Libras (Língua Brasileira de Sinais) nos currículos dos cursos de formação de profissionais de saúde em todos os níveis. Essa medida se traduziria numa ação incisiva de inclusão dos surdos como usuários plenos dos serviços de saúde oferecidos à sociedade e, portanto, um grande passo para minimizar, neste nível, as diferenças de um grupo de pessoas diferentes.

Palavras-chave: libras, surdos, ensino, profissionais de Saúde.

\section{Abstract}

Vulnerable groups in Brazil, still suffer impediments to access basic services provided by society. Among these are health care services, which become more uncertain about individuals belonging to such groups. Among these groups, the deaf people which many times are not correctly attended and even some times, infringed on its rights, because health services have not trained personnel to correctly attend them. The solution is discussed in this work, showing to be more efficient and sensible, the inclusion of the discipline of LIBRAS (Brazilian Sign Language) in the curricula of training courses for health workers at all levels. This measure would lead to effective action to include the deaf as full users of health services offered to society and therefore, a big step to minimize, at this level, differences of a group of different people.

Keywords: Libras, deaf, teaching, health professionals.

\footnotetext{
${ }^{1}$ Mestrando - Mestrado Profissional em Ensino em Ciências da Saúde e do Meio Ambiente - UniFOA

${ }^{2}$ Doutor - Mestrado Profissional em Ensino em Ciências da Saúde e do Meio Ambiente - UniFOA

${ }^{2}$ Fiocruz - Instituto Oswaldo Cruz, RJ
} 


\section{INTRODUÇÃO}

Desde o final do século passado, o mundo voltou seu olhar para os grupos categorizados como vulneráveis ou especiais. Tais grupos representam aqueles indivíduos portadores de necessidades especiais, ou seja, com algum tipo de deficiência que os impedem total ou parcialmente de participar plenamente das atividades sociais regulares. A sociedade está repleta de exemplos de deficiências.

Estima-se que de um total de 151 milhóes e meio de brasileiros, no mínimo dez por cento apresentam algum tipo de deficiência. (Capovilla, Macedo, \& Raphael, 1998).

Atualmente, os componentes dessa casta são cada vez mais incentivados a serem incluídos definitivamente nas atividades e nos serviços que o sistema oferece a todos. Assim, novos modelos de inclusão são propostos e testados a todo tempo, como vagas específicas em escolas, universidades e concursos públicos.

Segundo Rinaldo Correr 2003, "A comunidade deve aprender que, quando um de seus membros nasce com deficiências, todos os demais membros devem assumir juntos o compromisso de construir um ambiente inclusivo." As pessoas com deficiências representam um sinal de que todos somos diferentes, e que essa diferença, antes de ser algo negativo, pode nos levar a termos atitudes mais tolerantes com tais dificuldades.

Assim sendo, o Sistema de Saúde Pública, não pode abrir mão de se adequar às necessidades dessa clientela, a fim de que possa prestar a ela , serviços de atendimento digno em todos os seus níveis de atuação.

Dentre os grupos dos portadores de deficiências especiais, estão inseridos os deficientes auditivos ou surdos. Em termos de deficiência auditiva, existem no Brasil mais de dois milhôes e 250 mil casos (Capovilla, Macedo, \& Raphael, 1998). Tais pessoas, além serem alvo de preconceito, são clientes ainda não incluídos totalmente no Sistema de Saúde da maioria dos municípios do país. Isso porque os serviços de Saúde não se adequaram ao atendimento específico a esta clientela, a qual se encontra incluída em vários outros setores da sociedade em que vivem.

A forma mais comum de comunicação entre pessoas é a língua falada. A transferência de conhecimento se faz através dela. Os surdos têm essa forma de comunicação tradicional afetada. Isso faz com que os mesmos tenham como língua padrão, as linguagens através de gestos, que utilizam a visão como fonte receptora desses gestos corporais em sua formaçáo. A falta de comunicação oral torna o surdo desintegrado da sociedade ouvinte, tendo dificuldades de usufruir serviços básicos, como, por exemplo, acesso a hospitais, já que os ouvintes também têm dificuldades em entender a língua dos sinais.
Em decorrência de tais fatos, a proposta que se torna necessária é que os profissionais da Saúde, principalmente aqueles componentes da Atenção Básica e da Saúde da Família sejam capacitados para se comunicarem de maneira eficiente com tais clientes. Essa capacitação se concretizaria na oferta de cursos de LIBRAS (Língua Brasileira de Sinais) a todos os profissionais de Saúde de tais áreas, para que pelo menos esses profissionais tenham um mínimo de entendimento necessário para o atendimento do paciente.

Assim, dentro dessa temática, o presente trabalho tem como objetivo, a partir de um levantamento de material já publicado, discutir a necessidade de se incluir a Língua Brasileira de Sinais nos currículos dos cursos da área de Saúde.

\section{A LÍNGUA BRASILEIRA DE SINAIS (LIBRAS)}

No caso dos surdos, faz-se necessário franquear-lhes a palavra, quer dizer, antes de escreverem nosso idioma, deveriam poder se narrarem em sinais, e suas narrativas precisariam ser acolhidas por uma escuta também em sinais. (Souza,2000:92)

A Língua de Sinais foi, durante muito tempo, deixada em segundo plano dada a preocupação de pais e professores de surdos em ensiná-los a falar. Somente nos fins da década de 1950, é que a Língua de Sinais passou a ser valorizada e novamente pôde ser encarada de forma especial. Ela é uma língua completa e estruturada como tantas outras línguas (Sacks, 1998).

A Língua de Sinais não é uma língua universal, e da mesma forma que a línguagem oral, difere nos vários países, podendo até mesmo apresentar sinais que variam regionalmente ou entre comunidades de surdos de uma mesma localidade (Rocha \& Stumpf 1996).

Há algum tempo, os movimentos de surdos estão conquistando vários espaços com relação à educação e a língua de sinais brasileira. Porém, essas novas conquistas precisam se traduzir em açôes que permitam aos surdos o acesso aos saberes sistematizados por ouvintes. Por outro lado, os ouvintes podem e precisam ter acesso aos saberes produzidos pelos surdos. (CEFET, 2007)

Um marco significativo que demonstra o avanço das conquistas dos movimentos dos surdos está claramente mencionado no Decreto Lei no 5.626, de 22 de Dezembro de 2005, que regulamenta a Lei no 10.436 , de 24 de abril de 2002, dispondo sobre a Língua Brasileira de Sinais Libras, e o art. 18 da Lei no 10.098, de 19 de dezembro de 2000, reconhecendo a Libras como idioma das comunidades surdas do Brasil.

Capovilla \& Raphael, 2001, definem que a língua de 
sinais da comunidade surda brasileira é a Língua de Sinais Brasileira, também chamada LIBRAS.

Trata-se de uma língua viso-espacial com princípios formacionais únicos. Em abril de 2002, a Presidência da República sancionou a Lei Federal 10.436, decretada pelo Congresso Nacional, que oficializa a Libras em todo o território nacional (Ministério da Educação, 2002).

Essa lei reconhece a LIBRAS como meio de comunicação e expressão das pessoas surdas do Brasil, determina que o poder público se empenhe no apoio e difusão do seu uso, que as instituiçóes públicas prestem atendimento aos surdos em LIBRAS e que os sistemas educacionais incluam o ensino da LIBRAS como parte dos Parâmetros Curriculares Nacionais nos cursos de formação de Educação Especial, Fonoaudiologia e Magistério, nos Ensinos Médio e Superior. (Capovilla et al, 2004)

\section{O ENSINO DE LIBRAS NOS CURSOS DA ÁREA DE SAÚDE}

Em relato recente, a representante das Mulheres Surdas Brasileiras, Shirley Vilhalva (no site www.aleitamento. com), explicou que teve intérprete na sala do parto durante o nascimento de sua filha, mas teve dificuldades durante sua estada no hospital e, por falta de comunicação, não recebeu as orientaçóes que são dadas às mães ouvintes sobre a amamentação. Em outra situação relatada, um cliente com infecção venérea (Comunicaçâo pessoal) foi examinado na presença da sua intérprete, uma mulher, o que causou grande constrangimento a ambos.

O Decreto $n^{\circ} 5.626 / 05$ tornou obrigatória a inclusão de Libras nos currículos dos cursos de graduação em fonoaudiologia e nos que formam professores, como as licenciaturas e a pedagogia. Além disso, o MEC apoiou universidades a criarem o curso de graduação em Letras, com licenciatura em Libras, mas os primeiros alunos só estarão formados em quatro anos.

Portanto, as instituições de ensino estão tomando as providências necessárias para inserir a disciplinas de Libras em seus currículos, pois o decreto instituiu prazos para que todos os cursos atendam à determinação.

Uma solução a médio e longo prazos, seria a inclusão da LIBRAS como disciplina obrigatória em todos os cursos da área de saúde, visto que hoje, ela é ofertada apenas em alguns deles como disciplina eletiva e não tem atraído a atenção dos alunos que, compreensivelmente, sem informaçóes profundas sobre sua relevância, preocupam-se apenas com as disciplinas obrigatórias para a conclusão de seus respectivos cursos.

Em experiências relatadas de cidades que já oferecem tal diferencial aos profissionais de Saúde, constata-se a riqueza e relevância não só no aspecto do relacionamento interpessoal, mas também no aprimoramento da própria LIBRAS, pois a linguagem dos sinais é um idioma em desenvolvimento, pronto para incorporar a todo tempo novos verbetes que irão se traduzir em novos sinais ou gestos, aumentando assim cada vez mais sua capacidade de comunicação entre seus usuários. Por exemplo, muitas vezes, durante um curso voltado a profissionais da Saúde, o instrutor, como deficiente auditivo, não sabia como explicar determinada palavra ou procedimento médico-hospitalar por não existirem sinais específicos passíveis de identificaçáo pelo surdo. A partir dessa necessidade detectada, criou-se dentro da linguagem de sinais, novas palavras, colaborando para o dicionário de LIBRAS, através da criação de uma apostila com sinais específicos apropriados referentes a área de saúde.

Por outro lado, ao incorporar a LIBRAS como disciplina regular em grades curriculares dos cursos, a mesma seria alvo de estudos acadêmicos que iriam contribuir para o seu aprimoramento didático-científico em níveis que proporcionariam um avanço significativo de seus conteúdos e, consequentemente, de sua aplicabilidade prática.

Portanto, está definitivamente justificada a total relevância da capacitação em LIBRAS para os que atuam na área de Saúde, desde a recepcionista até o médico, face às necessidades de comunicação entre o profissional e os pacientes surdos, otimizando a interação e a troca de informaçôes, o que vem possibilitar uma assistência mais humanizada, mais resolutiva. Trabalhando assim, com primazia, o princípio básico do Sistema Único de Saúde, que é o de atender a todos conforme suas particularidades, especificidades, expectativas e necessidades.

\section{CONSIDERAÇÓES FINAIS}

Vivemos em mundo globalizado, em que as açóes adotadas para o conforto e o bem-estar das pessoas estão atreladas ao desenvolvimento integral do ser humano, fortalecendo o conceito de que o progresso da civilização não pode caminhar emancipado do crescimento do cidadão em todos os seus aspectos. Portanto, as açóes que possibilitem a inclusão de grupos de pessoas especiais, para que possam ter acesso aos serviços da sociedade como todos os cidadãos comuns, devem sempre ser vistas como processos equalizadores, pois objetivam minimizar, no âmbito social, uma deficiência herdada que, por muitas vezes, impede esse cidadão especial de usufruir serviços básicos disponíveis a todos, em todos os níveis de suas necessidades. Porém, não podemos definir inclusão como tentativa de transformar o incluído, incluir não é dar oportunidade para que eles mostrem sua capacidade, pois isso, não precisa ser provado, a boa inten- 
ção não é inclusão. Inclusão é incluir pelos talentos e não pelas limitaçóes. Todas estas pessoas querem e devem ser vistas como diferentes e não deficientes.

Os surdos compóem uma parcela desses cidadãos menos favorecidos em termos de acesso aos benefícios da sociedade, principalmente no que diz respeito ao atendimento em Saúde. Os relatos aqui transcritos comprovam que o atendimento prestado ao surdo sempre é precário devido à falta de preparo dos profissionais de saúde para lidar com tais diferentes. Quando se diz falta de preparo, devemos entender, não como falta de jeito ou aptidão, mas sim deficiência de embasamento teórico-prático na formação acadêmica do profissional para desempenho de sua atividade nesta situação. Os currículos atuais das profissóes da saúde, não contemplam tal competência, o que isenta de dolo as açôes de tais profissionais.

Por outro aspecto, a política atual sinaliza definitivamente para a inclusão de alunos considerados com necessidades educativas especiais, como os surdos, no ensino regular, nos diversos níveis, o que pode, em curto prazo, também propiciar ao profissional de Saúde a convivência no trabalho com equipes cujos membros sejam surdos, o que levaria a outro viés da importância de se ter pelo menos noçôes básicas de LIBRAS para um bom desempenho profissional, como na orientação de um procedimento ou até mesmo na discussão de um caso clínico. Mais uma vez se consolida a importância da língua de sinais para o exercício das profissões da área da saúde.

Portanto, o que se recomenda é que os profissionais de saúde tenham, nos currículos de seus respectivos cursos, incluída a disciplina de Libras, não como eletiva, mas sim como crédito obrigatório. Tal medida, num futuro próximo, proporcionaria a aquisição de saberes que iriam modificar as atitudes destes profissionais em relação ao atendimento prestado aos clientes surdos, aos seus familiares, assim como também uma maior interação em situaçóes de convívio profissional com colegas surdos, o que contribuiria sobremaneira para uma otimização da atuação do profissional, da atenção à saúde e do ato de cuidar.

\section{REFERÊNCIAS}

CAPOVILLA, F.C; MACEDO, E.C.; RAPHAEL, W.D. Manual Ilustrado de Sinais e sistema decomunicaçáo em rede para Surdos. Instituto de Psicologia da Universidade de São Paulo, São Paulo, SP,1998.

CORRER, R. Deficiência e Inclusáo Social: Construindo uma nova comunidade. Edusc. Bauru. SP. 2003
SOUZA, R. M. Práticas alfabetizadoras e subjetividade. Em Surdez - Processos Educativos e Subjetividade. Cristina Broglia Feitosa Lacerda e Maria Cecília Rafael de Góes (org.) Lovise. São Paulo. 2000.

Sacks, O. Vendo Vozes: Uma Viagem ao Mundo dos Surdos. Trad. Laura Teixeira Motta. Companhia das Letras. São Paulo. 1998

\section{CEFET. Cadernos Pedagógicos e DVD’s Para o Ensino} de Libras. Santa Catarina.2007

BRASIL. Presidência da República. Casa Civil Subchefia para Assuntos Jurídicos - Decreto no 5.626, de 22 de dezembro de 2005. Regulamenta a Lei no 10.436, de 24 de abril de 2002, que dispóe sobre a Língua Brasileira de Sinais - Libras, e o art. 18 da Lei no 10.098, de 19 de dezembro de 2000 .

CAPOVILLA, F.C; RAPHAEL, W.D. Dicionário Língua de Sinais Brasileiros. São Paulo. .SP. Edusp. 2001

CAPOVILLA, A. G. S.; GÜTSCHOW, C. R. D.; CAPOVILLA, F. C. Habilidades cognitivas que predizem competência de leitura e escrita. Psicol.: Teor. Prát., São Paulo, 2004.

ROCHA, A. C. AND STUMPF M. R. Sistema de Representaçáo Interna e Externa das Línguas de Sinais. Artigo submetido ao $2^{\circ}$ Congresso Iberoamericano de Comunicatión Alternativa y Aumentativa. Viña del Mar. Chile. 1996

Endereço para Correspondência:

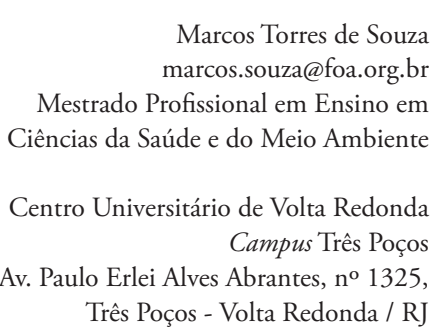

CEP: 27240-560 